\title{
Funding penalty for cross-boundary work
}

[LONDON] University departments whose 'structures' do not match those followed by Britain's Research Assessment Exercise (RAE), the regular initiative used as a basis for calculating funding allocations to universities, appear to get systematically lower research ratings.

According to an independent report on interdisciplinary research, nearly a quarter of university departments in the last Research Assessment Exercise either split their researchers between assessment panels, or sought cross-referral between panels.

The report found that such 'boundary critical' submissions received on average a 0.5 -point lower rating than non-critical submissions. The RAE rates departments on a 5point scale, and there are serious financial consequences for those that receive a reduced rating, particularly at the top of the scale.

The report, by consultancy Evaluation Associates, was commissioned by the four regional higher education funding bodies in preparation for the next Research Assessment Exercise, due to take place in 2001. It says of submissions that were cross-referred and split between panels that "our concern is that assessment in these circumstances is inherently difficult for panels. They are not considering entire departments but potentially arbitrary subsets of departments".

But the report also says that it found no evidence that RAE inhibits interdisciplinary research, despite a widely held conviction by researchers that it does. It did find a lack of consistency in the treatment of interdisciplinary research by individual panels, however.

"I've never had any problem with [the RAE] and I don't think it is a problem," says one interdisciplinary researcher involved with the next RAE. "In the area I operate, there is no disadvantage and I am extremely involved in interdisciplinary research."

Bahram Bekhradnia, director of policy at the Higher Education Funding Council for England (HEFCE) - which was responsible for the last exercise - says that interdisciplinary work "has always been one of the more difficult aspects of the exercise which is a discipline-based process. This was one of the reasons for the review."

He said that the report gave general comfort to interdisciplinary researchers, and that the funding council "expected to imple- ment" the specific recommendations. The report recommends new mechanisms for boundary critical submissions, and monitoring mechanisms to "ensure the effectiveness of cross-referral”.

Anita Jackson, a member of the RAE 2001 team, says that the assessment process is "evolutionary", and that the next exercise will take on board the recommendations of the report. "We will ask departments to say if their units do not fit. We have put in mechanisms where anything cross-referred will happen straight away - which was not what happened in the past."

It remains to be seen whether this will impress departments that feel they were badly rated in the last exercise. "We are aware that if anyone feels aggrieved they can have a judicial review," says David Pilsbury of HEFCE. But he points out that "it happened once before, and the outcome was in our favour".

The report finds that the RAE has encouraged researchers to concentrate on the quality of their research, but that they are doing more research that produces results in the short rather than long term. NatashaLoder

\section{Australia boosts medical research, but keeps other budgets level}

[CANBERRA] For the first time in his four budgets, the Treasurer of Australia's centreright Coalition government, Peter Costello, has highlighted the importance of science and research in his speech to Parliament, delivered in Canberra on Tuesday (11 May).

As foreshadowed by Prime Minister John Howard last week, medical research was given star billing in the budget, and is scheduled for a boost of A $\$ 614$ million (US\$404 million) over six years.

But other research budgets have been kept roughly at this year's levels. And the Science and Technology Awareness Program, which, among other activities, supported National Science Week, and cost A \$3 million in the past year, is being shelved "pending review".

As a result of the extra money for medical research, the National Health and Medical Research Council will have doubled its current budget of A $\$ 161$ million by the year 2005. "We as a government are very excited [about this]," said Costello. "It will put us at the cutting edge to really develop new industries."

The boost to medical research is the first outcome of a year-long review of health research that was chaired by businessman Peter Wills. Further recommendations from the panel are expected to be approved by the government shortly.

But although the medical and other

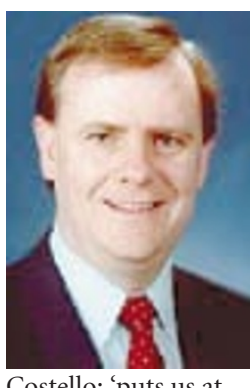

Costello: 'puts us at the cutting edge'. programme for biotechnology, which had been tipped to receive an extra $\mathrm{A} \$ 60$ million, will only receive $\mathrm{A} \$ 17.5$ million over two years - and this is earmarked not for research but for "development of a comprehensive new biotechnology strategy".

But the government promised to use some of the funds to set up a senior ministerial council "to manage the biotechnology agenda" and establish a statutory office to regulate the industry.

University infrastructure, long a subject of complaint from academic circles, is scheduled to receive an increase of $A \$ 93$ million, to bring total funding to $\mathrm{A} \$ 288$ million over three years. But this merely reverses cuts foreshadowed previously, and seems to be balanced by falls in other education programmes.
Funding of research grants remains steady pending the conclusion of a major review of the Australian Research Council.

Nick Minchin, the Minister for Industry, Science and Resources, has negotiated level funding for three national agencies operating under his aegis, the Commonwealth Scientific and Industrial Research Organization, the Australian Nuclear Science and Technology Organization (to which he gave final approval for a new research reactor last week), and the Australian Institute of Marine Science.

The annual Australia Prize, costing A $\$ 800,000$, will be continued to 2000-01 only because of its "significant lead times", according to a budget document.

Bob McMullan, shadow minister for industry and technology in the Labor Opposition, attacked the government for "hiding overall decreases" across several portfolios with stakes in science and technology by not releasing the annual science and technology budget statement on Tuesday.

Brian Anderson, president of the Australian Academy of Science, says the academy is "delighted with the result in medical research". But he says universities are still underfunded, and "there are no measures to reverse the downward trends in research by industry". 